The TESOL Quarterly invites commentary on current trends or practices in the TESOL profession. It also welcomes responses or rebuttals to any articles or remarks published here in The Forum or elsewhere in the Quarterly.

\title{
20 Years of the TESOL Quarterly
}

\section{JOHN SWALES}

University of Michigan

This article reports the results of a diachronic study of the flagship publication of the TESOL organization, the TESOL Quarterly (TQ). A flagship periodical in any field is worth more than cursory interest because it self-evidently is something more than a passive reflector of contemporary trends and issues. The gatekeeping activities of editors-and of those called upon to serve as reviewers-set standards of scholarly and professional behavior and establish areas of greater concern. Although a major periodical is partly shaped by wider forces in the disciplinary culture, it also shapes that disciplinary culture by the way it goes about its business.

One obvious way of studying the 20-year development of a periodical is to construct a historical account. Here the investigator would largely tell the story of the periodical from within: the circumstances of its founding, its growth and development, its internal crises and key points of transition-and such events set against the wider background of the story of the rise and fall of movements, enthusiasms, and research fronts (see Bowers, 1986). In the pursuit of such a historical narrative, the historian is likely to spend time in interviewing key figures and in examining archival documents and will do so with the laudable and reasonable ambition of relating cause and effect. In particular, the journal historian, like his or her counterparts in the history of knowledge, is likely to give special importance to attribution-wherein the $T Q^{\prime} s$ pages did a particular concept first surface, and out of who's head?

As it happens, I have had neither the time nor the right kind of experience to be able to construct such a narrative. My own contacts with TESOL and the TQ are both short-lived and peripheral in comparison with those of many others. On the other hand, I have some familiarity with the procedures of citational analysis (Small, 1982), and Swales (1986) was an attempt to apply 
qualitative procedures to the English as a second language/English for special purposes controversy surrounding Communicative Syllabus Design (Munby, 1978). The present study is more quantitative; in effect, this means that the approach is archaeological rather than historical, for it examines, by stratified sampling, the surviving textual record. It investigates the pictures on the wall of the cave but has nothing to say as to why or how those artifacts come to be there. Although there is little doubt that editors, publishers, and prophets can all play critical roles, the approach I have adopted may be able to discern certain broader trends, perhaps divorceable from the influence of particular protagonists.

A direct inspiration for the present study was Bazerman's (1984) analysis of spectroscopic articles in the Physical Review, 1893-1980. Following Bazerman, I examine the textual product in a broadbrush kind of way, even if I do not report for the TQ on some of the things that Bazerman investigated, such as syntactic, lexical, and rhetorical changes over time, and even if I have extended Bazerman's procedures to include authorship characteristics and a comparison of the $T Q$ and its peer periodicals.

\section{PROCEDURE}

This analysis is based on a selection of main articles across the history of the TQ. All other textual material, such as review articles, reviews, brief reports, and The Forum, has been excluded. The analysis starts with the main articles of Volume 2 (1968) - in the belief that after four issues the $T Q$ would have found its feet-and then includes all the main articles at subsequent 4-year intervals until 1984. I also examined in somewhat more detail the first three issues of 1986 (1986, No. 4, contains an unusual composite on "Alternatives in Second Language Research," and that issue was therefore excluded). The procedure produced a corpus of 192 main articles, of which the following features were investigated:

1. Authorship characteristics in terms of gender, number, location, and present occupation

2. Article length and the degree and type of macrostructuring into sections

3. The use of set-off nonprose material under such headings as Figure No. X or Table No. Y

4. The number of references per article and per 1,000 words of main text and the types of references cited (books, articles, chapters, etc.) 
5. The provenance of the references in the first three issues of the TQ, 1986

6. The citational status of the TQ (1977-1985) and its status in comparison with other periodicals (1985 only)

\section{MAIN RESULTS AND DISCUSSION}

Table 1 shows the percentage of single authors or first authors (of two or more) who are female. As the table makes clear, the data show a rise from $26 \%$ to $70 \%$ in the 18 -year period, with a strong increase in this decade. It looks as though before 1980 the majority of single/first authors were men, but since then, the majority have tended to be women. It would be nice to think that the greater representation of women more closely reflects their preponderance in the ESL profession.

Table 2 gives the percentage of articles that are single authored. Single-authored main articles still constitute a majority, but the percentage has moved downward from $92 \%$ in the early years to $62 \%$ in 1986. The increase in multiple-authored articles is possibly due to a partial shift from a humanities to a social science orientation as witnessed by a rise in quantitative research (Henning, 1986). The actual average number of authors has increased from 1.08 in 1968 to 1.48 in 1986 (Nos. 1-3), but the 1986 average still remains well below the average of around three authors per article commonly reported for the sciences.

TABLE 1

Percentage of Articles with a Female Sole or First Author

\begin{tabular}{cccccc}
\hline \hline 1968 & 1972 & 1976 & 1980 & 1984 & 1986 \\
\hline 26 & 42 & 39 & 33 & 64 & 70 \\
\hline
\end{tabular}

TABLE 2

Percentage of Single-Authored Articles

\begin{tabular}{cccccc}
\hline \hline 1968 & 1972 & 1976 & 1980 & 1984 & 1986 \\
\hline 92 & 92 & 78 & 74 & 65 & 62 \\
\hline
\end{tabular}

THE FORUM 
An analysis of 19 two-authored articles published in the TQ, 19841986, shows that in all but 2 articles at least one of the authors held a professorial position. The other authors in these 17 professorially authored articles were fairly equally distributed among instructors/ teachers (7), students or ex-students (5), and professors (5). This pattern seems to suggest that diverse individuals perceive an advantage in collaboration, irrespective of a contemporary trend to downgrade co-authored articles in promotion/tenure decisions for professorial appointments in the humanities.

The data for Figure 1, which gives the geographical location of first/single authors, were derived from the biographical notes accompanying articles and refer to the current location as described in those notes. The figure shows the consistent preponderance of North American locations (United States and Canada) and offers little evidence of any diminution of U.S.-located domination of the $T Q$. Canada is the only other country that gets on the graph at all. Particular country locations outside North America occur only occasionally. According to this sample, there is no country outside North America that has a tradition or track record of having its ESL specialists appear as authors of main articles in the $T Q$.

FIGURE 1

U.S. and Canadian Authors

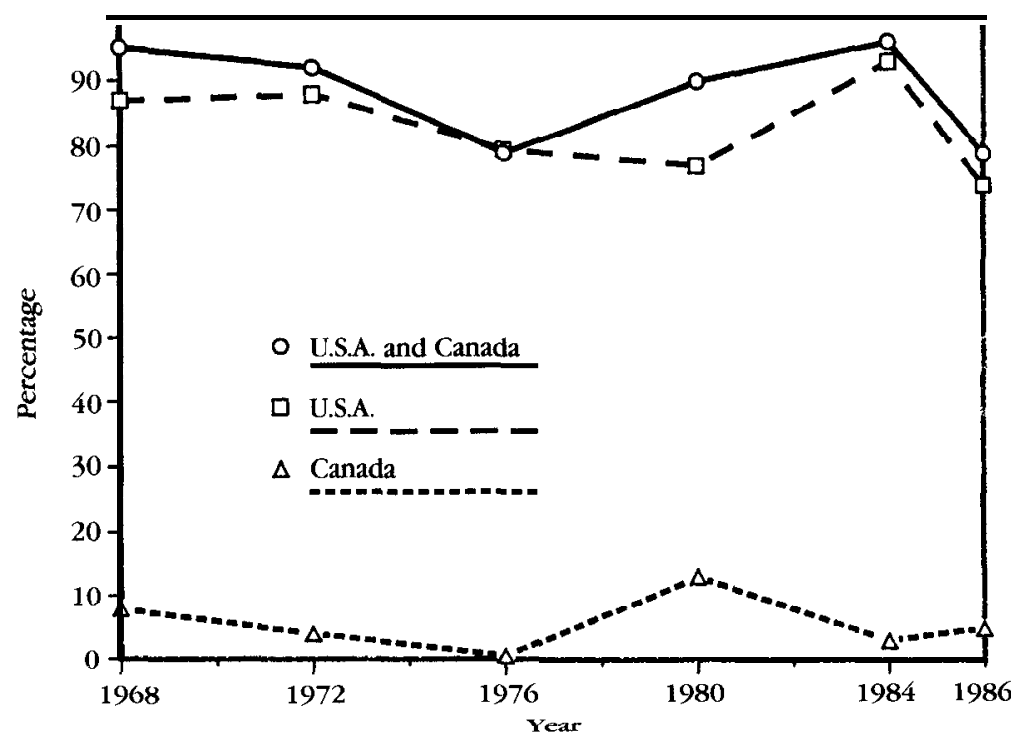


Figure 2 summarizes the types of occupation of single or first authors, who were placed into one of six categories:

1. University faculty (those with professorial posts in U.S. and U. S.based administrations, or lecturers and professors in U.K. and U.K.-based administrations)

2. University staff (those with instructor or lecturer positions in U.S. and U.S.-based systems; tutors in U.K. and U.K.-based systems)

3. University students

4. School instructors, whether public or private

5. Professionals, such as inspectors, translators, or testers

6. Others, such as those retired or working in non-ESL-related areas

The last four categories produced relatively few first/single authors, and as can be seen from Figure 2, the combined percentage for the first two categories has increasingly predominated (from around $75 \%$ to around $90 \%$ during the $1968-1986$ period). The figure also shows for the present decade some fall in faculty authorship and some rise in staff authorship. This trend may be due to increasing opportunities for staff to carry out the major studies that we typically expect of $T Q$ main articles; alternatively, it may reflect the increasing difficulty that PhD holders have been experiencing in obtaining tenure-track positions.

Overall, the authorship data suggest that a clear majority of $T Q$ main articles have, throughout the periodical's history, been written by university-based North Americans. The $T Q$ never was a journal written by teachers for teachers. In addition, there is evidence of a strong continuing trend toward female authorship and a weaker trend toward multiple authorship.

Table 3 provides data on the average length of the main articles during the 1968-1986 period. The figures are for the average length of the main text and exclude abstracts, tables, references, and appendixes. If we leave aside the 1968 average, there has apparently not been such a strong trend toward increasing length of main text as I suspect many readers of the $T Q$ would have anticipated. There has, however, been some standardization: For example, the 1972 peak is partly accounted for by the existence of two very long articles (around 12,000 words). Certainly, the later articles look longer because of the increasing numbers of tables, references, and appendixes, but if length is defined in terms of the main prose text, current averages are still under 6,000 words. 
FIGURE 2

Employment Status of Authors

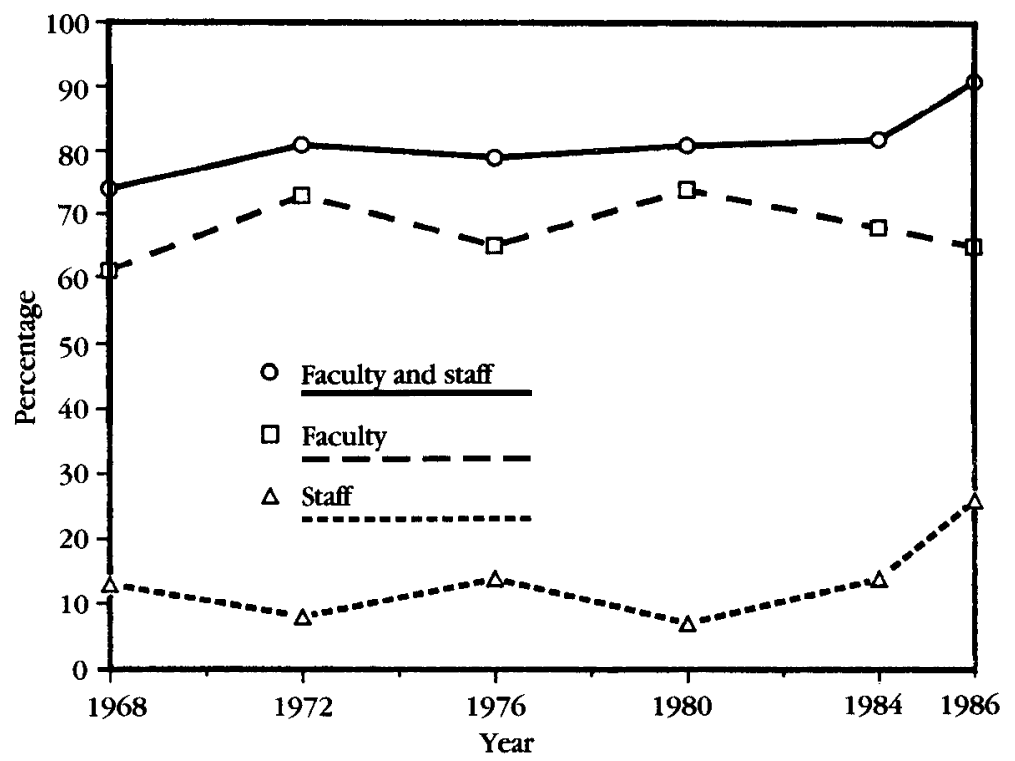

TABLE 3

Approximate Average Length of Articles (in Words)

\begin{tabular}{cccccc}
\hline \hline 1968 & 1972 & 1976 & 1980 & 1984 & 1986 \\
\hline 2,700 & 4,800 & 3,500 & 4,500 & 5,800 & 5,100 \\
\hline
\end{tabular}

During the life of the $T Q$ there have been greater changes in sectioning and in the use of set-off nonprose material. The unsectioned main article was originally the norm (80\%) but declined sharply and by 1984 had disappeared. Since 1972, sectioned articles have had a fairly steady average of about four top-level sections (as currently represented by large capitals). The percentage of articles without titled tables or figures has also declined (from $80 \%$ to $30 \%$ ), and the average number of such items per article has steadily risen from under 1 to about 2.5. Numerical tables have consistently provided the majority of the set-off items; thus, the $T Q$ has not evidenced the trend toward graphs that Bazerman (1984) noted for the Physical Review.

During the $T Q^{\prime} s$ existence there have been interesting developments in reference patterns. First, unreferenced main articles were 
always infrequent (a maximum of $24 \%$ in 1968) and have now disappeared. Concomitantly, there has been strong growth in the average number of references per main article, from 4 in 1968 to 34 in 1986 (see Table 4). A plateau can be seen in the 1972-1980 period, largely brought about by variability in citation practice. For example, of the 28 main articles published in 1976, half contained 10 or fewer references, 5 had between 11 and 20, 3 between 21 and 30, 5 between 31 and 50, and 1 with more than 50 references. Thus, in 1976, almost a quarter of the articles were highly referenced-if we accept that 30 or more references constitute a high degree of referencing. The main change that had occurred by 1984 was the virtual disappearance of main articles with 10 or fewer references, rather than an increase in references at the upper end of the scale.

Because articles vary in length, a somewhat more adequate indication of the upward trend can be achieved by examining the number of references per 1,000 words of main text. Table 5 shows a steep-and accelerating-rise from 1.6 to 7.0 references per 1,000 words.

TABLE 4

References per Main Article

\begin{tabular}{cccccc}
\hline \hline 1968 & 1972 & 1976 & 1980 & 1984 & 1986 \\
\hline 4 & 17 & 16 & 17 & 30 & 34 \\
\hline
\end{tabular}

TABLE 5

References per 1,000 Words of Main Article

\begin{tabular}{cccccc}
\hline \hline 1968 & 1972 & 1976 & 1980 & 1984 & 1986 \\
\hline 1.6 & 3.5 & 4.5 & 3.7 & 5.1 & 7.0 \\
\hline
\end{tabular}

References in the corpus were classified according to the following categories: (a) scholarly or teacher reference books, (b) textbooks (for ESL students or others), (c) chapters in edited books, (d) articles in journals and presentations, (e) technical reports and monographs, (f) dissertations and theses, (g) tests, (h) audiovisual materials such as tapes or films, (i) reviews, (j) literary works, and (k) others. Only the first four categories were prominent. Figure 3 shows a slow decline in the percentage of references that are made to scholarly or teacher reference books and the virtual elimination 
of references to textbooks. This latter trend would seem to suggest that $T Q$ main authors no longer consider ESL textbooks as primary sources of information or authority.

FIGURE 3

Types of Reference to Longer Works

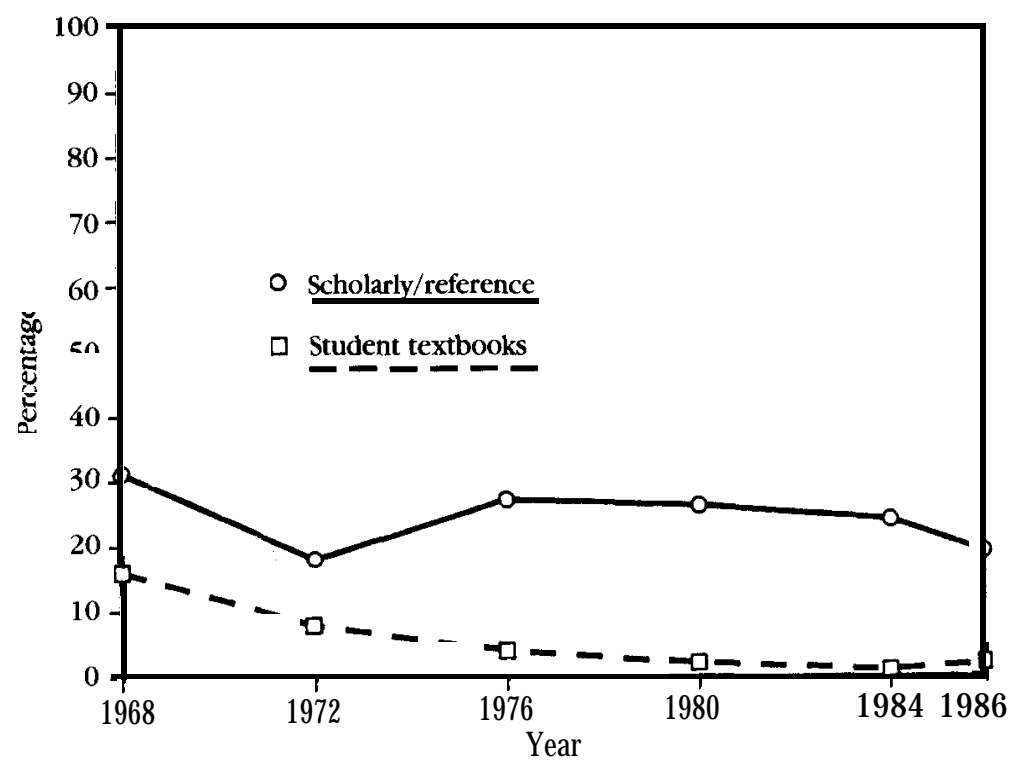

In contrast there has been a rise (see Figure 4) in the proportion of references made to short scholarly or research pieces as typically represented by articles and chapters. Indeed, the combined percentages for Categories $\mathrm{c}$ and $\mathrm{d}$ have increased from $30 \%$ to about $65 \%$ over the $1968-1986$ period.

I also examined in some detail the main classes of references in the main articles in the first three issues of 1986: references to journal articles and references to scholarly/teacher reference books or to chapters therein. In both cases I venture to suggest that the findings are not without interest.

In the 1986 corpus as described, there are 290 references to journal articles. These 290 references are spread around a remarkable total of 96 different journals, which represents a very low token-type ratio of 3:1. This wide spread may reflect either a vibrant interdisciplinary eclecticism or the existence of isolated authorial subgroups.

Two journals tower above the others: the $T Q$ with 53 references (the high self-citation rate in the $T Q$ is taken up later) and Language 
FIGURE 4

Types of Reference to Shorter Works

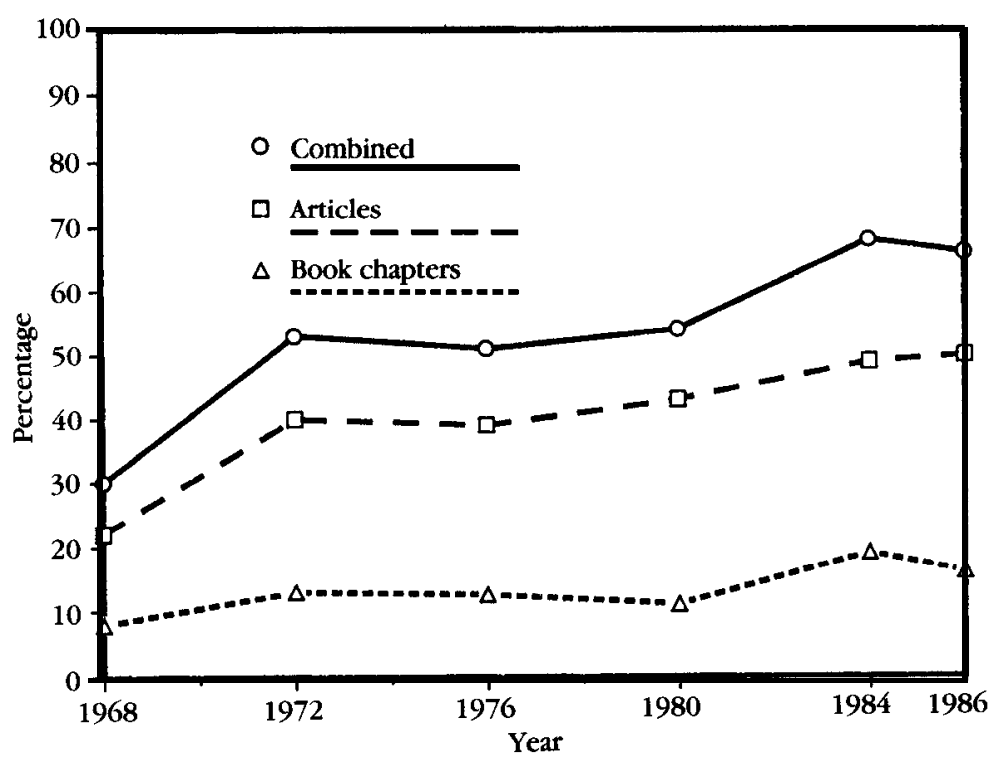

Learning with 43 . The remaining $67 \%$ of the 290 references are distributed among 94 journals. The leaders of the pack, as well as a crude approximation of the constituencies they principally serve, are presented below, in order of journals cited most frequently (after the TQ and Language Learning):

Modern Language Journal - foreign language teaching

International Review of Applied Linguistics - applied linguistics

College Composition and Communication- Ll writing

English Language Teaching Journal- ESL

System- ESL

Language - linguistics

There then follows a group of periodicals concerned with educational research, educational psychology, and psychology.

Thus far we have apparently seen a predominance of citations to journals that are concerned in varying proportions with language learning. One would then expect that each of the areas represented by these journals would have a large number of citations. However, if we examine the total list of journals (minus 11 that contain 12 references and fall into the category of miscellaneous), this expectation is not borne out. Indeed, the broader picture of which 
journals $T Q$ authors in the sample cite shifts quite dramaticallyeven assuming that I may have sometimes erred in placing a particular journal within a particular specialty. In the area of linguistics there is a total of 9 references (5 journals); in foreign language teaching, 23 references (6 journals); in English as an Ll, 26 references (12 journals); and in applied linguistics, 20 references (6 journals). Citationally, in 1986 the TQ's strongest links appear to be with educational and psychological research, for which there are 77 references (44 journals).

However, the most interesting finding relates to ESL journals themselves-at first sight "natural" sources of references for articles submitted to the TQ. There are, in fact, but 10 ESL journals cited and a low total of 27 references (very similar figures for English as a first language). How can we account for the phenomenon that the authors in the sample find little citable in ESL journals other than the TQ itself (and Language Learning in so far as it is concerned with ESL)?

The most plausible answer seems to be that the $T Q$ is considered largely self-sufficient as a source of appropriate and relevant ESL journal citations, and indeed the high TQ self-citation rate would support such a speculation. Of course, this is not to imply that the 1986 authors consider the TQ as a self-sufficient source of ESL citations in general because considerable reference is made to ESL scholarly and teacher reference books (both edited and authored). What it does suggest is that there is no strong interest in incorporating findings from ESL journals that in some sense represent other regions of the world, findings from the JALT Journal and the RELC Journal for Asia, from System for continental Europe, from the English Language Teaching Journal for Britain and the Commonwealth, or from TESL Canada.

I also investigated the country of publication of books cited. There were 240 such books, of which 181 were published in the United States (75\%) and 59 (25\%) elsewhere, mostly Britain (39) followed by Canada (8). There were only three outside North America/Western Europe (Egypt, 2; Singapore, 1). Most striking is the low visibility of publishers in Western Europe, especially in Holland, where we know that several publishing houses are active in linguistics and allied fields.

So far I have concentrated on the $T Q^{\prime} s$ internal practices. I would now like to consider its role in the wider world. What is the $T Q^{\prime} s$ record as a cited journal? For this we can look for enlightenment to the final and seventh volume of the annual Social Science Citation Index (SSCI). The figures for the 1977-1985 years, which are (as is customary in the $\mathrm{SSCl}$ ) based on all citations, not just those found in 
main articles, are presented in Table 6. For example, the SSCI survey found 55 citations to the $T Q$ in 1977, 16 of which were made in 1977 to previous articles in the TQ by TQ authors and 39 of which were made in 1977 by authors of articles published in other journals.

TABLE 6

S.SCl Citations of the TQ( 1977-1985 )

\begin{tabular}{lccc}
\hline \hline Year & Total & $\begin{array}{c}\text { Citations of the } \\
T Q \text { in the } T Q\end{array}$ & $\begin{array}{c}\text { Citations of the } T Q \text { in } \\
\text { other journals }\end{array}$ \\
\hline 1977 & 55 & 16 & 39 \\
1978 & 88 & 40 & 48 \\
1979 & 123 & 56 & 67 \\
1980 & 101 & 26 & 75 \\
1981 & 148 & 54 & 94 \\
1982 & 131 & 38 & 93 \\
1983 & 196 & 83 & 113 \\
1984 & 227 & 91 & 136 \\
1985 & 242 & 126 & 116 \\
\hline
\end{tabular}

The previous section has illustrated that references in the $T Q$ have been steadily increasing; according to the $S S C l$ count of all references, these climbed from 451 in 1977 to 1,119 in 1985 (with a big jump between 1982 and 1983). This represents an increase of almost $150 \%$, whereas total citations to the $T Q$ have increased from 55 to 242 , an increase of just under $350 \%$. It therefore looks as though the $T Q$ is becoming a more influential periodical in absolute terms (i.e., in terms of increasing citations) as well as in relative terms (i.e., the growth in citations to the $T Q$ is increasing faster than the growth in the TQ). However, such a straightforward account cannot be sustained if we consider the figures in the last two columns in Table 6.

Clearly, references to the $T Q$ within the $T Q$ have been growing faster than references to the $T Q$ in other journals: The percentage increase for the former is almost $700 \%$, whereas for the latter it is almost $200 \%$. It therefore appears that the citational success of the $T Q$ is at least partly due to its own self-perpetuating tradition rather than being simply ascribable to the periodical's increasing significance for the authors who publish in a broader coterie of periodicals.

Indeed, we can see some confirmation of this when we compare the $1985 \mathrm{TQ}$ figures with those for a number of comparable journals. (The TQ- relevant fields are comparatively small. A 
powerful and prestigious journal like Language collected over 700 citations in 1985, and a giant in a giant field, The American Economic Review, stacked up more than 5,000 citations to itself.) Table 7 shows that the $T Q$ belongs in the peer-group "big four" as far as total 1985 citations are concerned. However, if we examine citations to the TQ that are not self-citations, it can be seen that the $T Q$ evinces the greatest place drop of all 10 journals-from third to sixth. It may be, of course, that the 1985 figures will turn out to be anomalous when data for 1986 are available. Certainly, a possible contributing factor to the $T Q^{\prime} s$ high self-citation rate is the encouragement of interactive commentary such as Forum-type replies and responses, which are bound to increase journal selfcitation.

TABLE 7

SSCI Citations of Selected Journals (1985)

\begin{tabular}{lcccc}
\hline \hline \multicolumn{1}{c}{ Journal } & Total & Rank & $\begin{array}{c}\text { Citations } \\
\text { other than } \\
\text { self-citations }\end{array}$ & Rank \\
\hline Language Learning & 296 & 1 & 235 & 2 \\
Language and Speech & 262 & 2 & 241 & 1 \\
TQ & 242 & 3 & 116 & 6 \\
Language in Society & 239 & 4 & 210 & 3 \\
Research in the Teaching of English & 182 & 5 & 132 & 4 \\
Modern Language Journal & 157 & 6 & 130 & 5 \\
Foreign Language Annals & 144 & 7 & 103 & 7 \\
Canadian Modern Language Review & 100 & 8 & 39 & 10 \\
Applied Psycholinguistics & 99 & 9 & 88 & 8 \\
Applied Linguistics & 83 & 10 & 58 & 9
\end{tabular}

\section{EVALUATION}

Finally, is there, in the light of this rather odd study, cause for celebration after 20 years and 80 issues? I will look at this by trying to answer four questions.

1. Is the $T Q$ a major journal? In terms of peers in the applied language arts and sciences, the answer is yes, even if the affirmative is qualified by the abnormally high self-citation rate.

2. Is the $T Q$ a journal of research and scholarship? The answer is clearly yes (see Gaies, 1987, for an interesting discussion of the research "issue"). 
3. Is the $T Q$ an international journal? Given the fact that ESL is a major global activity, the answer is no, at least in any geographic sense of international.

4. Does the $T Q$ represent the profession? In terms of demonstrating to a wider world that ESL is too serious a business to be left to native-speaker amateurs, the answer is yes.

Certainly the rather dry facts that I have presented attest to growth and development in all kinds of ways (except for international aspects). Of course, as I mentioned at the outset, these facts are limited to textual, biographical, and citational features. A more complete study of the first 20 years of the TESOL Quarterly would also involve at least an analysis of its content, but that requires investigators with a greater courage in their categorical convictions. ${ }^{1}$

\section{REFERENCES}

Bazerman, C. (1984). Modern evolution of the experimental report in physics: Spectroscopic articles in Physical Review, 1893-1980. Social Studies of Science, 14, 163-196.

Bowers, R. (1986). English in the world: Aims and achievements in English language teaching. TESOL Quarterly, 20, 393-410.

Gaies, S.J. (1987). Research in TESOL: Romance, precision, and reality. TESOL Newsletter, 21 (2), 21-23.

Henning, G. (1986). Quantitative methods in language acquisition research. TESOL Quarterly, 20, 701-708.

Munby, J. (1978). Communicative syllabus design. Cambridge: Cambridge University Press.

Small, H. (1982). Citation context analysis. In B. Dervin \& M.J. Voight (Eds.), Progress in communication sciences (Vol. 3, pp. 287-310). Norwood, NJ: Ablex.

Swales, J. (1986). Citation analysis and discourse analysis. Applied Linguistics, 7, 39-56.

\footnotetext{
1I would like to thank my assistants Jennifer Marwill, Shigeru Mori, Pan Fang Fu, and Carol Tower for their help in analyzing the main data; Douglass Scott and Robert Blue for help with the graphics; Dr. Henry Small of the Institute for Scientific Information, Philadelphia, for important advice at a critical juncture; and an anonymous reviewer who wrote a valuable, two-page commentary.
} 